\title{
(c) (1) \\ BIOÉTICA DE INTERVENÇÃO APLICADA À PESSOA COM DEFICIÊNCIA, PERSPECTIVAS TEOLÓGICAS E INCLUSÃO NA COMUNIDADE
}

\author{
Intervention applied to the person with disabilities bioethics, theological perspectives \\ and inclusion in the community
}

\author{
Elizabete Aparecida Pereira \\ Pontifícia Universidade Católica do Paraná \\ Mestranda em Teologia - Bolsista CAPES \\ elizabete.aparecida@pucpr.br \\ Sérgio Junqueira \\ Pontifícia Universidade Católica do Paraná \\ Professor Titular, Livre Docente em Ciência da Religião. \\ srjunq@gmail.com
}

RESUMO: Sob o intuito de aferir de que modo a pessoa com deficiência guarda relação com as categorias da Escola de Pensamento Bioético Intervencionista trabalhadas pelos bioeticistas Dora Porto e Volnei Garrafa, o artigo analisa o desenvolvimento da Bioética, que expandiu seus limites para além da seara médica, atingindo o campo social a partir das noções de corporeidade, empoderamento, libertação e emancipação, perpassando tratados internacionais de direitos humanos. Resultando a revisão literária numa conformação das categorias analisadas à realidade das pessoas com deficiência, buscando a contribuição da Teologia para o debate bioético, sobretudo, no campo da Teologia Moral, o artigo deságua no modelo que confere 'opção preferencial pelos pobres', emergindo a categoria vulnerabilidade como referencial da Bioética em sua dimensão social, a partir das perspectivas de pobreza e exclusão. Contrariando a visão errônea das pessoas com deficiência como objeto de caridade e de assistencialismo, a teologia latino-americana posiciona-as como sujeitos de um mundo desafiado à construção de uma nova sociedade, fraterna e solidária, atenta às suas especificidades e necessidades, em todas as dimensões da vida, inclusive espiritual.

Palavras chave: Pessoa com deficiência; Bioética de Intervenção; Teologia.

ABSTRACT: Under the objective of assessing how the disabled person is related to the categories of Interventional Bioethical Thought School worked by bioethicists Dora Port and Volnei Bottle, the article analyzes the development of bioethics, which expanded its boundaries beyond the harvest medical, reaching the social field from corporeality notions of empowerment, liberation and emancipation, passing international treaties on human rights. Resulting literary review in conformation of the categories analyzed the situation of people with disabilities, seeking the contribution of theology to the bioethical debate, especially in the field of moral theology, the product flows into the model that gives 'preferential option for the poor', emerging from the category vulnerability as a reference of bioethics in its social dimension, from the perspectives of poverty and exclusion. Contrary to erroneous view of disabled people as objects of charity and welfare, the Latin American theology positions them as subjects of a challenged world to build a new society, brotherhood and solidarity, attentive to their specificities and needs in all the dimensions of life, including spiritual.

Keywords: Person with disabilities; Intervention Bioethics; Theology. 


\section{Introdução}

O Relatório Mundial da Deficiência publicado em 2011 pela Organização Mundial de Saúde - OMS aponta $15 \%$ da população mundial com algum tipo de deficiência, o que corresponderia a mais de um bilhão de pessoas, a maior minoria do mundo, sendo $80 \%$ vivendo países em desenvolvimento. Já os resultados do Censo Demográfico 2010 do Instituto Brasileiro de Geografia e Estatística - IBGE indicam que 45.606.048 de pessoas declararam possuir pelo menos um tipo de deficiência, correspondendo a $23,9 \%$ da população brasileira1.

Se por um lado a estatística apresentada permite aferir o quantitativo de pessoas com deficiência, do ponto de vista conceitual, consoante a Convenção Internacional dos Direitos da Pessoa com Deficiência, aprovada em 3 de maio de 2008, na cidade de Nova York, são assim consideradas aquelas que têm impedimentos de longo prazo de natureza física, mental intelectual ou sensorial, os quais, em interação com diversas barreiras, podem obstruir sua participação plena e efetiva na sociedade em igualdade de condições com as demais pessoas.

Segundo Miranda $(2005,13)$, todos são pessoas com deficiência em potencial, pois na medida em que se envelhece é possível apresentar limitações de ordem sensorial, motora ou mental, constatação esta que expressamente consta do Relatório retrocitado, quando afirma que a deficiência faz parte da condição humana na medida em que "quase todas as pessoas terão uma deficiência temporária ou permanente em algum momento de suas vidas, e aqueles que sobreviverem ao envelhecimento enfrentarão dificuldades cada vez maiores com a funcionalidade de seus corpos”.

O conceito apresentado pela Convenção Internacional reconhece a diversidade das pessoas com deficiência, porquanto não alude apenas ao cadeirante, mas também ao cego, surdo, autista, dentre tantos outros, clarificando que a deficiência não reside na pessoa, mas no meio que a circunda.

Todo esse contingente possui uma série de direitos estampados na referida Convenção (vida, saúde, habilitação e reabilitação, educação, trabalho, assistência social, participação na vida cultural e recreação, lazer e esporte, acesso à justiça,

\footnotetext{
${ }^{1}$ Considerando cada tipo de deficiência isoladamente, 1,4\% da população possui deficiência mental; 7\% tem deficiência motora; 5,1\% apresentam possuem deficiência auditiva e 18,8 informaram deficiência visual, o que eleva o percentual para $32,4 \%$ da população.
} 
prevenção contra exploração, violência e abuso, liberdade de expressão e de opinião, dentre outros), não obstante o presente artigo aborde especificamente o direito e desafios à inclusão na comunidade, que não pode excluir a dimensão religiosa, a partir da chave de leitura Direitos Humanos desenvolvida como categoria estudada pela Bioética de Intervenção pelos bioeticistas Dora Porto e Volnei Garrafa.

Nesta perspectiva, sem a pretensão de esgotar o assunto, mas tão somente configurar um ponto de partida para a efetivação de direitos da pessoa com deficiência, busca-se responder em que medida essa Escola de Pensamento Bioético guarda relação com esse segmento da sociedade e de que modo esta relação implica na inclusão na vida comunitária, numa dimensão religiosa.

\section{A Bioética de intervenção no contexto da bioética}

Facco et al. $(2010,2)$ tecem uma breve retrospectiva sobre a história da Bioética, cujo termo surgiu em 1970 na obra Bioethics: The Science of Survival e Bioethics: Bridge to the Future, do biólogo e oncologista Van Tensselaer Potter, evidenciando que a partir do avanço da medicina, sobretudo a tecnologia biomédica, estas não estavam dissociadas de valores éticos, daí a necessidade de reflexão em torno de uma ética que levasse em conta as conquistas da ciência que afetam a vida humana, compreendendo ' $a$ necessidade de um novo paradigma de ciência que pudesse unificar a biologia, as humanidades e a ciência social'.

Reconhecida na $33^{\text {a }}$ Conferência geral da UNESCO realizada em Paris, no ano de 2005, mediante referendo e aclamação por 191 países integrantes das nações Unidas, a Bioética não alcançou esse intento sem antes um caminho trilhado por avanços e recuos, pois até então a bioética era muito contextualizada nos campos biomédico e biotecnológico.

Três anos antes, durante o $6^{\circ}$ Congresso Mundial de Bioética, realizado em Brasília, promovido pelo Comitê Internacional de Bioética, juntamente com a Sociedade Brasileira de Bioética, foi criado o Dicionário Latino-americano de Bioética, ampliando os fundamentos teóricos bioéticos à realidade social, política e cultura da América Latina.

A bioética potteriana analisada no contexto essencialmente biomédico tinha 
como referência os princípios da autonomia ${ }^{2}$, da beneficência ${ }^{3}$ e da justiça $a^{4}$, com vistas à contenção de abusos ocorridos nos Estados Unidos quanto às pesquisas com seres humanos. Posteriormente sobreveio o princípio da não maleficência ${ }^{5}$.

Todavia, a Declaração Universal de Bioética e Direitos Humanos, homologada pela UNESCO, em outubro de 2005, altera a agenda da disciplina para o século XXI, construindo referências mais condizentes com a realidade e com os princípios éticos, com a biomédica assumindo proporções mais amplas, deixando o individualismo e especificidade do campo biomédico, para exigir a participação direta da sociedade civil, visando o bem estar das pessoas e das comunidades.

Partindo da premissa que a bioética não está limitada à área biomédica, a multiplicidade de áreas temáticas de discussão demanda a necessidade de superar a fragmentação do saber, permitindo a interdisciplinaridade e o diálogo na pluralidade.

A agregação de profissionais de diferentes áreas de conhecimento ao estudo da Bioética favoreceu a reflexão autóctone das várias escolas de pensamento bioético ${ }^{6}$. Abordando especificamente a Bioética da Intervenção, busca-se sua compreensão a partir dos marcos teóricos referidos por PORTO e GARRAFA (2005, p. 111-123), naquele que seria o seu documento referencial - Intervention bioethics: a proposal for peripheral countries in a context of power and injustice ${ }^{7}$, quais sejam: a corporeidade $\mathrm{e}$ os diversos tratados internacionais de direitos humanos, com ênfase na Declaração Universal de Bioética e Direitos Humanos. Posteriormente, a compreensão atingirá categorias individualmente tecidas pelo segundo bioeticista, não obstante todas sejam importantes para a conformação da Escola de Pensamento Bioético Intervencionista.

\footnotetext{
${ }^{2}$ Permite ao ser humano decidir sobre o que é bom ou o que é de seu bem-estar de acordo com seus valores suas expectativas, necessidades, prioridades e crenças, desde que com consciência e liberdade.

${ }^{3}$ Consiste em fazer o bem, cuidar da saúde e da qualidade de vida, ou seja, beneficiar as pessoas atendendo às suas necessidades básicas, o que seria uma ajuda ativa.

${ }^{4}$ Diz respeito à distribuição social igual ou equitativa, definida por normas justificadas.

5 Origina-se da ética médica e tem como ponto referencial antes de tudo não causar danos intencionalmente nos aspectos psíquico, social e moral, dente outros.

${ }^{6}$ Facco et al. (2010, 7-10) referem seis escolas do pensamento bioético brasileiro: bioética de reflexão autônoma; bioética de proteção; bioética de intervenção, bioética e teologia da Libertação; bioética feminista e bioética ambiental.

${ }^{7}$ Apresentado na sessão de abertura do Sexto Congresso Mundial de Bioética, em 2002.
} 


\title{
- Corporeidade
}

A corporeidade seria o primeiro parâmetro teórico e conceitual da Bioética de Intervenção na perspectiva de que qualquer abordagem ou dimensão a partir da qual se analisa o ser humano deve ser calcada sobre o corpo humano - não restrito à sua dimensão fisiológica - situando o prazer e a dor como indicadores da necessidade dessa intervenção, na medida em que:

\begin{abstract}
A bioética de intervenção defende a ideia de que o corpo é a materialização da pessoa, a totalidade somática na qual estão articuladas as dimensões física e psíquica que se manifestam de maneira integrada nas inter-relações sociais e nas relações com o ambiente. A escolha da corporeidade como marco das intervenções éticas se deve ao fato de o corpo físico ser inequivocamente a estrutura que sustém a vida social, em toda e qualquer sociedade. (PORTO e GARRAFA, 2005, 116).
\end{abstract}

Partindo da premissa de que a corporeidade não se restringe à dimensão fisiológica, Porto e Garrafa (op. cit., 117) referenciam a ideia de pobreza a partir de seres humanos que, cotidianamente experenciam a escassez dos meios indispensáveis a sua sobrevivência física e social, implicando uma privação de suas potencialidades e das condições estruturais básicas que propiciem a construção e realização dos seus próprios destinos.

\section{- A Declaração Universal de Bioética e Direitos Humanos}

Além da corporeidade, outro referencial norteador da bioética de intervenção são os diversos tratados internacionais de direitos humanos, neles identificando o absoluto essencial ao qual fazem jus todas as pessoas, pugnando "pelo direito de indivíduos, grupos e segmentos à equidade nas garantias legais e no acesso real aos direitos humanos" (op. cit., 118).

Dentre os diversos tratados sobre direitos humanos, a Declaração Universal de Bioética e Direitos Humanos, homologada pela UNESCO em outubro de 2005 será destacada pelos dois bioeticistas em artigos individuais.

Porto (2012, p. 111) refere a uma 'metamorfose da bioética pela abertura à perspectiva social', sendo recepcionada a ideia de que a bioética não pertence 
inequívoca e exclusivamente à área biomédica, o que passou a ser mais amplamente aceito no Brasil e no mundo a partir da publicação do referido Documento Internacional que, segundo a autora, ao estabelecer os direitos humanos entre os seus princípios, reconheceu a dimensão social como intrínseca à bioética, rompendo os limites que a circunscreviam.

Já Garrafa (2005, p. 130-131) aponta a Declaração Universal de Bioética e Direitos Humanos como sendo o documento que permitiu o avanço da bioética em sua relação com a justiça social, consistindo num marco redefinidor da agenda bioética para o século XXI, generosamente ampliando seu campo de análise, pesquisa e ação, a partir dos tópicos abordados no seu bojo, que versam acerca da dignidade humana e direitos humanos; respeito pela vulnerabilidade humana e integridade pessoal; além dos princípios de igualdade, justiça e equidade.

Para o autor, as importantes conquistas obtidas no documento no campo da inclusão social contaram com a contribuição das firmes e legítimas ações políticas dos países latino-americanos. Neste eito, afirma na página 131 que a partir da referida Declaração, “a Bioética incursionou pela política para incluir as questões sociais em sua agenda. E isso não é biopolítica. É a bioética intervindo em uma dimensão mais ampla: a politica".

\section{- Inclusão social na epistemologia da Bioética a partir das categorias empoderamento, libertação e emancipação.}

Mas não é só. Em artigo individual Garrafa (op. cit., 126-127) também refere à bioética e sua relação com a justiça social a partir da discussão da inclusão social na epistemologia da Bioética.

Nesse especial, afirma que na seara da bioética, o tema da inclusão social é tratado de modo diferente por diversos autores, advertindo que a proposta que desenvolve pressupõe a ideia de uma ação social politicamente comprometida capaz de transformar a práxis social, definição esta que se coaduna aos marcos teóricos traçados pela Bioética de Intervenção.

Nessa perspectiva, o autor corrobora a necessidade de politização da bioética como ferramenta de construção da justiça social, trabalhando a inclusão social a partir das categorias empoderamento, libertação e emancipação, como possíveis instrumentos 
epistemológicos da Bioética de Intervenção.

A ideia de empoderamento estaria alicerçada na articulação orgânica entre os diferentes grupos e segmentos vulnerabilizados por conta do processo histórico e da característica cultural das sociedades nas quais estão inseridos, atuando como elemento capaz de amplificar as vozes dos segmentos alijados do poder de decisão, e promovendo sua inserção social ${ }^{8}$.

Especificamente em relação à libertação, o bioeticista compreende os sujeitos sociais como atores políticos, cuja ação pode desencadear a manutenção bem como a transformação do status quo, e advogando a necessidade da ação política concreta para a transformação social, pondera que:

\begin{abstract}
“A utilização desta categoria na Bioética de Intervenção pretende apontar em que direção se deve conduzir a luta política para garantir tal liberdade. Sua adoção visibiliza a luta das cidadãs e cidadãos que logram sua inclusão social, seja no contexto da saúde ou em contextos mais amplos, a partir da tomada de consciência sobre as forças que os oprimem e pela ação concreta em oposição a elas." (GARRAFA, 2005, 128).
\end{abstract}

Já em relação à categoria emancipação, o autor considera que esta se presta à Bioética de Intervenção como instrumento para direcionar a luta pela libertação, inserindo-a na dimensão coletiva. Nessa perspectiva, merece destaque a referência de que:

"Só é emancipado aquele que suprimiu sua dependência, que alcançou o domínio sobre si mesmo e pode garantir não apenas a sobrevivência, mas suas escolhas frente aos meios de alcançar essa sobrevivência. $\mathrm{O}$ poder sobre si mesmo é o que outorga a emancipação, tornando a pessoa imune às forças que buscam sua sujeição." (GARRAFA, 2005, 129).

Por fim, retomando o artigo conjunto de Porto e Garrafa (op. cit., 118), insta destacar que estes reconhecem que a bioética de intervenção ultrapassa o campo

\footnotetext{
${ }^{8}$ Perkins e Zimmerman (1995, p. 1) definem o empoderamento como "um construto que liga forças e competências individuais, sistemas naturais de ajuda e comportamentos proativos com políticas $e$ mudanças sociais". Para Horochovski e Meirelles (2007, 486), trata-se da constituição de organizações constituídas por indivíduos que participam democraticamente das questões que lhes dizem respeito, com voz, visibilidade, influência e capacidade de ação e decisão. Noutras palavras, equivale aos sujeitos terem poder de agenda nos temas que afetam suas vidas.
} 
estatal, pois seu discurso incorpora a cidadania expandida, "para a qual o referencial de legitimação e aceitação dos direitos não se restringe apenas às garantias asseguradas pelo Estado, mas estende-se à condição inalienável de pessoa, perpassando assim o conjunto das sociedades humanas".

\section{Bioética de intervenção aplicada à pessoa com deficiência}

Se nas palavras de Facco et al. $(2010,8)$ a Bioética de Intervenção tem como principal objeto situações persistentes originadas da desigualdade social, sob o viés da defesa dos cidadãos e cidadãs excluídos, como também dos mais vulneráveis, inevitavelmente é possível citar neste contexto as pessoas com deficiência.

Situada a Bioética da Intervenção no percurso da Bioética, é chegada a ocasião de demonstrar como as categorias trabalhadas por aquela Escola de Pensamento Bioético guardam relação ao referido segmento.

\section{- Novamente a corporeidade, empoderamento, libertação e emancipação.}

O marco referencial da corporeidade dispensa maiores comentários se considerarmos a definição de pessoa com deficiência trazida pela Convenção de Nova York. Partindo da afirmação de Porto e Garrafa (op. cit., 119), esse contingente populacional pode ser enquadrado como um dos "segmentos historicamente vulneráveis pela situação/condição de vida desfavorável na qual se encontram'.

Porto $(2012,123)$ novamente faz breve alusão a grupos que são constituídos por pessoas em estado de acentuada vulnerabilidade, exemplificando 'pessoas portadoras de necessidades especiais ${ }^{\prime 9}$, sendo que em decorrência da abordagem, merece destaque a reflexão de que:

Se o que se espera da bioética aplicada à dimensão social é que contribua para proporcionar equilíbrio de poder e oportunidades, não se deve perder de vista a importância de as escolhas individuais e as tomadas de decisão institucionais estarem voltadas ao bem da coletividade, considerada em sua

\footnotetext{
9 É muito comum que as pessoas com deficiência sejam incorretamente assim denominadas. Conceitualmente, o termo correto é Pessoa com Deficiência, expressão positivada no ordenamento jurídico brasileiro a partir da consagração pela Convenção Internacional sobre os Direitos das Pessoas com Deficiência.
} 
totalidade, promovendo-se assim equidade de acesso aos diferentes, ainda que não sejam maioria. Ao incluir também as necessidades dos 'diferentes' entre as prioridades de justiça se estará construindo uma dinâmica social orgânica e contemplando efetivamente o interesse comum. (PORTO, 2012, 124)

Se é o corpo físico que materializa a pessoa, mas não se reduz à dimensão fisiológica, sustentando a vida social, em toda e qualquer sociedade, a limitação corporal das pessoas com deficiência pode tolher potencialidades e condições estruturais básicas propiciadoras da construção e realização dos seus próprios destinos.

Em relação às categorias empoderamento e libertação, se os sujeitos sociais são atores políticos que podem promover uma transformação social por meio de suas ações, é importante destacar que no meio do segmento é corrente a expressão "Nada sobre nós sem nós", que implica o reconhecimento de que as pessoas com deficiência aspiram ao sentimento de sujeitos de sua história ${ }^{10}$, protagonismo este que é referido em diversos dispositivos da Convenção de Nova York.

Situando o bem-estar do ser humano como um fim, o cerne da bioética de intervenção permite a reflexão em torno da promoção da emancipação pessoal, uma das principais tarefas para a ação cidadã transformadora, nas dimensões individual e coletiva, a Convenção de Nova York também é muito clara ao afirmar a acessibilidade e autonomia como princípios que instrumentalizam a efetivação dos direitos, em especial o da inserção comunitária.

\section{- DEFICIÊNCIA E DIREITOS HUMANOS: a convenção de nova york enquanto tratado internacional específico para a pessoa com deficiência.}

Tendo como parâmetro a Constituição da República Federativa do Brasil de 1988, importa referir que o artigo $5^{\circ}, \S 3^{\circ}$ expressamente prevê que tratados $e$ convenções internacionais sobre direitos humanos aprovados, em cada Casa do Congresso Nacional, em dois turnos, por três quintos dos votos dos respectivos

\footnotetext{
${ }^{10}$ Hoje em dia, várias pessoas com deficiência estão se organizado para exigir cidadania. Paralelamente ao protagonismo da pessoa com deficiência, também há a sensibilização de seus familiares e amigos, sendo dignas de menção as APAES, que atuam em mais de dois mil municípios no Brasil, desenvolvendo ações que vão desde o atendimento direto até a conscientização da comunidade sobre as potencialidades do público atendido. Enfim, atualmente existe um vasto espectro de entidades de e para pessoas com deficiência.
} 
membros, serão equivalentes às emendas constitucionais.

Atendendo ao preconizado, a Convenção Internacional dos Direitos da Pessoa com Deficiência foi recepcionada no ordenamento jurídico com status de emenda constitucional.

Dentre vários pontos elencados no referido Documento Internacional, interessa para este artigo a efetivação do direito convencional e constitucional da vida Independente e inclusão na comunidade, estampado no caput do artigo 19, excerto da alínea 'b' e integralidade da alínea 'c':

Artigo 19 - Vida independente e inclusão na comunidade Os Estados Partes desta Convenção reconhecem o igual direito de todas as pessoas com deficiência de viver na comunidade, com a mesma liberdade de escolha que as demais pessoas, e tomarão medidas efetivas e apropriadas para facilitar às pessoas com deficiência o pleno gozo desse direito e sua plena inclusão e participação na comunidade, inclusive assegurando que:

b) As pessoas com deficiência tenham acesso a uma variedade de serviços de apoio em domicílio ... ou comunitários ... para que as pessoas com deficiência vivam e sejam incluídas na comunidade e para evitar que fiquem isoladas ou segregadas da comunidade;

c) Os serviços e instalações da comunidade para a população em geral estejam disponíveis às pessoas com deficiência, em igualdade de oportunidades, e atendam às suas necessidades.

Da forma genérica como é tratado na Convenção, o direito à inclusão em comunidade também implica a dimensão religiosa, não afastando o debate na seara da espiritualidade das pessoas com deficiência que, a toda evidência, também são Povo de Deus.

Ser pessoa precede a deficiência e esta é igualmente vocacionada para a vida em sociedade e para a salvação em Jesus Cristo.

Para Miranda (2005, 31), uma vez que 'a fé cristã fundamenta-se na especificidade e na alteridade úmica de cada pessoa', nisto reside também a sacralidade da pessoa com deficiência. 


\section{Perspectiva teológica da Bioética aplicada à pessoa com deficiência}

A reflexão tecida a partir das categorias apresentadas pelos bioeticistas ainda permite conformar a necessidade de, em relação à pessoa com deficiência, pensar a bioética voltada para as questões sociais numa perspectiva teológica.

Avançando a bioética de intervenção para além da seara médica, atingindo o campo das ciências humanas, neste ponto situada a Teologia enquanto tipo de saber que 'traz uma contribuição específica ao buscar a interpretação da vida nas dimensões espirituais do ser humano', daí sua 'importante parceira para a construção da bioética' (SILVA, 2013, 248).

Prosseguindo, adverte que o caráter inter ou multidisciplinar, sobretudo transdisciplinar, da bioética favorece o diálogo como elemento necessário no processo de reflexão, que não exclui nenhuma disciplina sendo, portanto, necessário descobrir o lugar da ética teológica dentro do conjunto das focagens possíveis no debate bioético caracterizando o contributo específico da Teologia neste debate multidisciplinar. (SILVA, 2013, 250)

Dialoga a bioética com a Religião, o que de resto já fora considerado por Van Rensselaer Potter, tanto em sua obra pioneira - Bioethics: bridge to the future -, em que cita como de grande relevância as percepções teológicas de Teilhard de Chardin, como também em publicações posteriores, em que referencia o interesse de Hans Küng em discutir uma verdadeira ponte entre a Ciência e a Religião (FILHO, ANJOS, 2011, 428429).

Sanches (2011, 175), ao dispor sobre a busca de uma relação entre bioética e teologia, percebe uma recorrência de questões teológicas fortemente debatidas naquela seara, elencando outros teólogos que marcaram a elaboração e consolidação da disciplina, não obstante compreenda que, hodiernamente, 'é a bioética que está sendo mais impactada pela teologia do que o inverso’.

À luz desta compreensão, importa inserir a Teologia no diálogo interdisciplinar da Bioética e de modo especial, no campo da Teologia Moral, o modelo de libertação, fruto de um processo de transformação nascido no continente latino-americano a partir das Conferências de Medellin e Puebla, identificando o compromisso preferencial da 
Igreja com os pobres, em cujo rosto sofrido vislumbra-se a injustiça e marginalização.

Neste modelo de moral a antropologia toma em consideração o 'não homem', que padece da miséria de que é vítima, plasmando o rosto desfigurado de crianças, jovens, indígenas, afro-americanos, camponeses, operários, sub e desempregados, idosos, pessoas com deficiência, dentre outros marginalizados e oprimidos.

Neste modelo que confere 'opção preferencial pelos pobres', emerge a categoria vulnerabilidade como elemento de referência da Bioética em sua dimensão social, a partir das perspectivas de pobreza e exclusão.

Segundo Peretti e Souza $(2012,107)$, não obstante a ênfase dada à problemática da vulnerabilidade na área da saúde, o conceito deve ser necessariamente um referencial em toda e qualquer avaliação bioética, seja neste campo como nas demais ciências.

Neste sentido, prestou a Teologia da Libertação enorme contribuição ao revelar a expressiva desigualdade existente na América Latina, optando preferencialmente pelos pobres, oprimidos e excluídos, sinalizando que algo deveria ser feito à transformação da sociedade, porquanto, 'para defender a vida é preciso, antes de tudo, devolver a vida àqueles excluídos dela' (PERETTI, SOUZA, 2012, 100-101).

No que pertine à pobreza, do ponto de vista teológico, como bem advertido por Gutierrez (apud SOBRINO, 2008, p.50), a Teologia da Libertação, 'para dizêe-lo em outros termos - como faz a Bíblia - foi-se atenta a não reduzir a pobreza ao seu aspecto, capital certamente, econômico'.

Assim, é plenamente possível dizer a deficiência como uma situação de vulnerabilidade social expressada pela pobreza, questão norteadora da teologia latinoamericana, pois independentemente de seu padrão econômico objetivo, sua condição em nosso mundo expressa um tipo de pobreza, não apenas no continente latino-americano, agravando ainda mais a situação quando a deficiência vem associada à carência de recursos materiais (FILHO, 2009, 58-63).

Portanto, a pobreza significa um terrível cerceamento da liberdade fundamental do ser humano, aspecto particularmente sensível para as pessoas com deficiência. (FILHO, 2009, 62)

A vulnerabilidade da pessoa com deficiência também está associada a uma realidade de exclusão e, como tal, 'vinculando-se às desigualdades existentes e, especialmente, à privação do poder de ação e representação' (WANDERLEY, 2007, 
104), permitindo estabelecer uma convergência entre a bioética da Teologia da Libertação e a de intervenção, na medida em que esta 'aponta para a necessidade de fomentar a libertação, sustentar o empoderamento e assegurar a emancipação dos sujeitos sociais, buscando assim alcançar sua inclusão plena na dinâmica relacional da sociedade' (PORTO, GARRAFA, 2011, 726).

\section{Considerações finais}

Conquanto os bioeticistas desenvolvam apenas perfunctoriamente a reflexão em torno da bioética da Teologia da Libertação, admoestam que tanto esta quanto a bioética de intervenção dizem respeito a sujeitos em coletividade ou particulares identificados como excluídos, vulnerados, oprimidos, que possuem seus direitos de cidadania tolhidos (PORTO, GARRAFA, 2011, 727).

Do ponto de vista teológico, na passagem de João 5, 1-9, a cura que Jesus realiza ao cego com a recomendação que ele carregue seu leito implica libertação e plena capacidade (emancipação), como sinal de dignidade.

O reconhecimento da dignidade existente em cada ser humano, nas palavras de Silva (2013, 251-252) reside no dado fundamental da antropologia cristã, cujo pensamente acentua aquele como criatura única e irrepetível, merecedora de respeito em qualquer situação, independente daquilo que pode oferecer.

E justamente o ser humano criado por Deus à sua imagem e semelhança é afirmação teológica que valora a sacralidade da vida humana que, segundo João Paulo II, consiste no coração da Teologia Moral (PERETTI, SOUZA, 2012, 109).

$\mathrm{Na}$ maioria das vezes, as pessoas com deficiência não são consideradas dignas de partilharem os seus dons, mas apenas destinatárias da caridade alheia, sob postura absolutamente passiva diante do assistencialismo.

Contrariando essa visão equivocada, a teologia latino-americana vem mostrar que os pobres, em especial aqueles com deficiência, têm algo a ensinar.

A partir das Conferências de Medellin e Puebla, os pobres até então objeto de caridade e de assistencialismo emergem como novos sujeitos sociais de um mundo solidário e fraterno, desafiando a construção de uma nova sociedade, cuja prática implica num compromisso sociopolítico transformador, com espeque na justiça e no 
amor.

Se a fé cristã coloca no centro das suas atenções os diminuídos, os doentes e os que estão em desvantagem, os excluídos (PERETTI, SOUZA, 2012, 110), essa predileção de Deus, já presente na Escritura e no Magistério da Igreja, precisa ser colocada em prática, atingindo também as pessoas com deficiência em suas especificidades e necessidades, em todas as dimensões da vida, inclusive espiritual.

\section{Referenciais}

BÍBLIA SAGRADA. ed. rev. e atual. São Paulo: Sociedade Bíblica do Brasil, 1996.

BRASIL. Constituição (1988). Constituição da República Federativa do Brasil: promulgada em 5 de outubro de 1988, com as alterações adotadas pelas Emendas Constitucionais nos 1/92 a 56/2007 e pelas Emendas Constitucionais de revisão nos 1 a 64/94. Brasília: Senado Federal, Subsecretaria de Edições Técnicas, 2008.

Decreto $\mathrm{n}^{\mathrm{o}}$ 5.296, de 02 de dezembro de 2004. Regulamenta as Leis $\mathrm{n}^{\mathrm{os}} 10.048$, de 8 de novembro de 2000, que dá prioridade de atendimento às pessoas que especifica, e 10.098, de 19 de dezembro de 2000, que estabelece normas gerais e critérios básicos para a promoção da acessibilidade das pessoas portadoras de deficiência ou com mobilidade reduzida, e dá outras providências. Disponível em <http://www.planalto.gov.br/ccivil_03/_Ato2004-2006/2004/Decreto/D5296.htm> Acesso em 12.11.2013.

Secretaria Especial dos Direitos Humanos. Coordenadoria Nacional para Integração da Pessoa Portadora de Deficiência. A Convenção sobre os direitos das pessoas com deficiência: versão comentada. RESENDE, Ana Paula Crosara; VITAL, Flavia Maria de Paiva, 2008, 165 p.

FACCO, Fernando; SCHNAIDER, Taylor, e SILVA, José Vitor. A Bioética: Histórico e Princípios. Enciclopédia Biosfera, Centro Científico Conhecer - Goiânia, V. 6, n.11; 2010, p. 1-11.

FILHO, Fernando Bortolleto. Deficiência e pobreza. Revista Caminhando. V. 14, n. 1, p. 57-64, jan. jun. 2009.

FILHO, José Marques; ANJOS, Márcio Fabri dos. Van Rensselaer Potter e a Religião na Bioética. Revista Bioethikos, Centro Universitário São Camilo - 2011; 5(4): 427433.

GARRAFA, Volnei. Inclusão social no contexto político da Bioética. Sociedade Brasileira de Bioética, V.1, n. 2, 2005, p. 122-132.

HOROCHOVSKI, Rodrigo Rossi; MEIRELLES, Giselle. Problematizando o conceito de empoderamento. Anais do II Seminário Nacional Movimentos Sociais, 
Participação e Democracia, 2007, UFSC, Florianópolis, Brasil. Disponível em: $<$ http://www.sociologia.ufsc.br/npms/rodrigo_horochovski_meirelles.pdf $>$. Acesso em 24.07.2015

IBGE. Censo Demográfico 2010. Fundação Instituto Brasileiro de Geografia e Estatística, dados referentes à população do Brasil. Disponível em: 〈http://www.censo2010.ibge.gov.br>. Acesso em 22.06.2015.

MIRANDA, Evaristo. Maravilhas a caminho: Acolher um deficiente, viver nossas deficiências. São Paulo: Loyola, 2005.

ORGANIZAÇÃO DAS NAÇÕES UNIDAS. A ONU e as pessoas com deficiência. Disponível em <http://www.onu.org.br/a-onu-em-acao/a-onu-e-as-pessoas-comdeficiencia/>. Acesso em 22.06.2015.

PERETTI, Clélia; SOUZA, Waldir. Bioética e Teologia e suas interconexões com as questões sociais. Estudos Teológicos São Leopoldo. V. 52, n. 1, p. 99-112, jan/jun. 2012. Disponível em <file://C:/Users/Juridico/Downloads/280-1379-1-PB\%20(1).pdf>. Acesso em 24.07.2015.

PERKINS, Douglas Demaree; ZIMMERMAN, Marc. Empowerment meets narrative: listening to stories and creating settings. American Journal of Community Psicology, 1995, oct., V. 23. n. 5.

PORTO, Dora; GARRAFA, Volnei. A influência da Reforma Sanitária na construção das bioéticas brasileiras. Ciência \& Saúde Coletiva, 16 (Supl.1): 719-729, 2011.

Bioética de intervenção: considerações sobre a economia de mercado. Bioética, 2005, Vol. 13, n. 1, p. 111-123.

Bioética de intervenção: retrospectiva de uma utopia. In GARRAFA, Volnei, et al. (Org.). Bioética, poderes e injustiças: 10 anos depois. Brasília: CFM/Cátedra UNESCO de Bioética/Sociedade Brasileira de Bioética, 2012.

SANCHES, Mário Antônio Sanches. Bioética e Teologia: Diálogo entre mínimos e máximos. Estudos Teológicos São Leopoldo v. 51 n. 1 p. 172-185 jan./jun. 2011

SILVA, Marcelo Antonio. Interface entre a Teologia Moral e Bioética - O serviço à vida humana. III Jornada Interdisciplinar de Pesquisa em Teologia e Humanidades. V. 3, N. 1, 2013. Disponível em: <file:///C:/Users/Juridico/Downloads/3jointh7736\%20(5).pdf>. Acesso em 24.07.2015.

SOBRINO, Jon. Fora dos pobres não há salvação: pequenos ensaios utópicoproféticos. São Paulo: Paulinas, 2008.

UNESCO. Declaração Universal sobre Bioética e Direitos Humanos. [online]. Paris, 19 out 2005. Tradução Cátedra Unesco de Bioética da Universidade de Brasília. 
Disponível

em:

<http://bvsms.saude.gov.br/bvs/publicacoes/declaracao_univ_bioetica_dir_hum.pdf >.

Acesso em: 22.06.2015.

XXXIII Conferência Geral da UNESCO, Paris, 2005. Disponível em http://portal.unesco.org/en/ev.php-

URL_ID=28354\&URL_DO=DO_TOPIC\&URL_SECTION=201.html

Acesso em 22.06.2015.

WANDERLEY, Mariângela B. e WANDERLEY, Luiz E. O social e a pobreza: visões e caminhos. In: Religião \& Cultura. 12, VI (2007): 99-119.

World Health Organization, The World Bank. Relatório Mundial sobre a Deficiência. Tradução Lexicus Serviços Linguísticos. São Paulo: SEDPcD, 2012.

Recebido: 05/10/2016

Received: 10/05/2016

Aprovado: 01/11/2016

Approved: 11/01/2016 